\title{
Rheological Characteristics of Municipal Thickened Excess Activated Sludge (TEAS): Impacts of pH, Temperature, Solid Concentration and Polymer Dose
}

\author{
Eugene Hong ${ }^{1}$, Anteneh Mesfin Yeneneh ${ }^{1}$, Ahmet Kayaalp ${ }^{2},{ }^{*}$ Tushar Kanti Sen ${ }^{1}$, Ha Ming Ang ${ }^{1}$, and Mehlika \\ Kayaalp ${ }^{2}$ \\ ${ }^{1}$ Department of Chemical Engineering, Curtin University, GPO Box U1987, Perth 6845, Australia \\ ${ }^{2}$ Water Corporation of Western Australia, West Leederville, 6007, Australia \\ *Corresponding author’s email: T.Sen@curtin.edu.au
}

\begin{abstract}
Rheological characterization of sludge is known to be an essential tool to optimize flow, mixing and other process parameters in wastewater treatment plants. This study deals with the characterization of thickened excess activated sludge in comparison to raw primary sludge and excess activated sludge. The effects of key parameters (total solid concentration, temperature, and $\mathrm{pH}$ ) on the rheology and flow behaviour of thickened excess activated sludge were studied. The rheological investigations were carried out for total solid concentration range of $0.9 \% \mathrm{w} / \mathrm{w}-3.7 \% \mathrm{w} / \mathrm{w}$, temperature range of $23^{\circ} \mathrm{C}-55^{\circ} \mathrm{C}$, and $\mathrm{pH}$ range of $3.6-10.0$. Different rheological model equations were fitted to the experimental data. The model equations with better fitting were used to calculate the yield stress, apparent, zerorate, infinite-rate viscosities, flow consistency index, and flow index. The decrease in concentration from $3.7 \% \mathrm{w} / \mathrm{w}$ to $3.1 \% \mathrm{w} / \mathrm{w}$ resulted in drastic reduction of yield stress from $27.6 \mathrm{~Pa}$ to $11.0 \mathrm{~Pa}$, and further reduction of yield stress to 1.3Pa was observed as solid concentration was reduced to $1.3 \% \mathrm{w} / \mathrm{w}$. The viscosity at higher shear rate $\left(>600 \mathrm{~s}^{-1}\right)$ decreased from 0.05Pa.s down to 0.008Pa.s when the total solid concentration was reduced from $3.7 \%$ to $0.9 \%$. Yield stress decreased from 20.1Pa down to $8.3 \mathrm{~Pa}$ for Bingham plastic model when temperature was raised from $25^{\circ} \mathrm{C}$ to $55^{\circ} \mathrm{C}$. Activation energy and viscosity also showed decreasing trend with increasing temperature. Yield stress of thickened excess activated sludge increased from a value of 6.0Pa to 8.3Pa when $\mathrm{pH}$ was increased from 3.6 to 10.0. The effect of polymer dose on the rheological behaviour of thickening of excess activated sludge was also investigated, and the optimum polymer dosage for enhanced thickener performance was determined to be $1.3 \mathrm{~kg} / \mathrm{ton}$ DS.
\end{abstract}

Key words: Thickened excess activated sludge, rheological model, yield stress, and polymer dose 1 


\section{Introduction}

Water consumption and demand for water resources is steadily increasing with the rapid population growth which has resulted in the increased production of wastewater and sewage sludge. Understanding flow behaviour and rheological properties of sludge are becoming increasingly important because of growing concerns for sustainable and efficient sludge management. Rheological characterization of sludge is important because of its influence on pumping, hydrodynamics and mass transfer rates. Hence, it proves to be an essential factor that affects process performance and plant economics [1].

Primary sewage sludge that flows into wastewater treatment plants is usually subjected to primary treatment of sedimentation and thickening followed by secondary biological treatment involving aeration and sedimentation. This process produces activated sludge which is mainly composed of microbial populations in flocculated form. The activated sludge has to be thickened in dissolved air flotation thickener before it is introduced to anaerobic digestion process for further degradation and stabilization of the sludge. This process highly relies on good solid and liquid separation within the thickener [2]. Thickened activated sludge, a product of the thickening process, is a very complicated colloidal material which is composed of organic and inorganic particles. The organic part of thickened sludge we studied consists of bacteria such as Pseudomonas, Flavobacterium, Acinetobacter, Achromobacter, Actinobacteria, but also protozoa and micromycetes, while the organic matter consists mainly of solid particles of sand [3]. The rheological and flow behaviour during the thickening of this complicated non-Newtonian pseudo-plastic fluid needs to be intensively investigated so as to optimize the performance of the thickening process, minimize the cost of polymer consumption and achieve maximum possible increase in total solid concentration of thickened activated sludge for efficient performance of the anaerobic digesters. The present study investigates different factors affecting the rheology of thickened excess activated sludge, namely source, total solid concentration, $\mathrm{pH}$, temperature, and sludge treatment methods [4-6].

Total solid concentration is a factor that influences the rheology and flow behaviour of thickened excess activated sludge significantly. Baroutian, et al. [7] and Farno, et al. [8] investigated the effect of total solid concentration and temperature on sludge rheology and found that yield stress increased with increasing solid concentration and decreased with increasing temperature. The increase in shear stress with solid concentration was observed to be more noticeable at higher shear rates. According to Einstein's Law of Viscosity, the existence of solids suspended in a fluid increases 2 
its viscosity [9]. Sludge characteristic curve for low solid concentrations differs from that for high solid concentration where there is a strong interaction between solid particles. Depending on the solid concentration, activated sludge shows a slightly thixotropic and shear-thinning behaviour [10].

Temperature is another factor that influences the rheological properties of thickened excess activated sludge. Thermal energy results in a change of the shape, size and strength of flocculated particles, and the degree of their dispersion. These changes directly influence the rheological properties of sludge [9]. Viscosity is generally lower with higher temperature and shear rate $[8,11,12]$.

$\mathrm{pH}$ is another parameter that influences the network strength of flocs particularly for colloidal systems such as thickened excess activated sludge. $\mathrm{pH}$ of solution affects the surface charge of particles which in turn determines the strength of inter-particle forces and hence changes the rheological properties of the thickened excess activated sludge $[13,14]$.

In a typical wastewater treatment plant, the thickening of excess activated sludge is achieved with the help of a polymer based flocculation agent in dissolved air flotation thickeners. These polymer or chemical additives can alter the floc size-density-structure relationship and affect the settling performance and phase separation of activated sludge system. Hence, determination of the optimum dose of polymer for enhanced settling performance is essential [2]. Therefore, established rheological data is required for the optimization of polymer consumption and enhancement of the cost effectiveness of the process [15].

Rheological measurement are conducted by using rheometers which establishes a relationship between shear stressshear rate and viscosity-shear rate [1]. It is considered to be difficult to obtain reliable rheological measurement due to great variability within the sludge sample, measuring method and devices used. Hence, a uniform measurement protocol is required to improve the reliability and repeatability of the data. Furthermore, rheological measurements are valuable data for system analysis by translating the data into mathematical equation which describes the system [1, 4]. According to Ratkovich, et al. [1] and Eshtiaghi, et al. [11], there are no model which fit perfectly with any sludge samples and there are no clear indication that yield stress exist within sludge samples but it is widely accepted that rheological model which includes a yield stress term can be used to represent flow behaviour within a limited shear rate range. Many researchers focus on investigating the rheological behaviour of different types of sludge. 
However, due to the colloidal and complex nature of sludge, the parameters measured may show high variability. Particularly for activated sludge, results may not be consistent and replicable. The rheology of thickened excess activated sludge is different for each wastewater treatment plant. Very few researchers report the rheological behaviour of thickened excess activated sludge in their studies. There is also a need to optimize the polymer dose required for thickening of excess activated sludge to make the process more cost effective. Hence, the present research focuses on investigating the rheological behaviour of thickened excess activated sludge and the impacts of different factors such as temperature, $\mathrm{pH}$, solid concentration, and polymer dose on the rheological behaviour and other physico-chemical characteristics that are required for efficient operation in wastewater treatment processes.

\section{Material and Method}

\subsection{Collection of sludge and characterization}

Thickened excess activated sludge (TEAS) samples were collected from the underflow of a dissolved air floatation unit at Beenyup Wastewater Treatment Plant of Water Corporation, Perth, Western Australia. Excess activated sludge (ES), raw primary sludge (RPS), and a mixture of raw primary and thickened excess activated sludge (MS) were also collected from the same wastewater treatment plant. Intensive characterization was conducted on each of the collected samples. The characterization of sludge involved determination of physico-chemical and biological parameters such as total solids content (TS), total volatile solids (VS), chemical oxygen demand (COD), temperature, and $\mathrm{pH}$. Standard Methods for Examination of Water and Wastewater provided by the American Public Health, et al. [16] were used for the study. pH was measured with WP-90 and WP-81 conductivity/TDS-pH/temperature meter equipped with a glass electrode (TPS, Australia) [9]. Total chemical oxygen demand was determined by using oxidation method with HACH COD reagent and colorimetric analysis on an ORION UV/Vis spectrometer [17]. Total solids (TS) and total volatile solid (VS) content were determined by employing the standard gravimetric method [18].

\subsection{Rheometry}

Concentric cylinder geometry is more suitable to be used for the sludge sample obtained for this study. Furthermore, the gap size needs to be larger than the largest particle of the sludge samples but small enough as to avoid settling of particles [1, 11]. The samples collected was found to have surface-weighted mean of $125 \mu \mathrm{m}$. For this study, a 4 
Discovery Hybrid Rheometer G-2 (DHR-2) equipped with TRIOS analysis tool was used. The rheometer was fitted

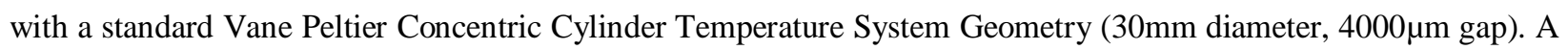
shear rate range of $0-1000 \mathrm{~s}^{-1}$ was used, and temperature was controlled between $23^{\circ} \mathrm{C}$ to $55^{\circ} \mathrm{C}$. The rheological measurement cycle consisted of four major steps: a) conditioning step of $120 \mathrm{~s}$ at shear rate of $5 \mathrm{~s}^{-1}$ at each desired temperature, b) An equilibration phase of 30s, c) 'Flow Step' using a logarithmic ramp until maximum shear rate is reached, d) shear rate was reduced to zero. An average volume of $35 \mathrm{ml}$ of sludge sample was placed into the concentric cylinder (sample holder) which is equipped with Peltier heating and cooling system. The rheological investigation for all sludge types, raw primary sludge (RPS), excess activated sludge (ES), thickened excess activated sludge (TEAS), and mixture of raw primary and thickened excess activated sludge (MS) were conducted under the same conditions described in this section.

\subsection{Rheological modelling}

Ideal fluids show linear flow and are classified as Newtonian fluids. Non-Newtonian fluids do not show a linear flow behaviour due to their complex structure and deformation effects [19]. Non-Newtonian fluids are diverse and can be characterised as e.g. pseudoplastic, viscoplastic, dilatant and thixotropic fluids. Several rheological models are used for non-Newtonian fluids to determine important rheological parameters such as shear stress, yield stress, flow index, infinite and zero-rate viscosities and flow consistency index [20].

Shear stress and viscosity models such as Bingham, Ostwald, Herschel-Bulkley, Sisko, Careau, and Cross models, shown in equations (1), (2), (3), (4), (5), and (6) respectively, have been used extensively to characterize viscoplastic fluids like sludge which show pseudo plastic shear thinning behaviour [1, 21, 22].

$$
\begin{aligned}
\tau & =\tau_{y}+\eta_{B} \dot{\gamma}^{n} & & \frac{\mu-\mu_{\infty}}{\mu_{0}-\mu_{\infty}}=\left(1+(\lambda \dot{\gamma})^{2}\right)^{\frac{n-1}{2}} \\
\tau & =K \dot{\gamma}^{n} & & \frac{\mu-\mu_{\infty}}{\mu_{0}-\mu_{\infty}}=\frac{1}{1+(\lambda \dot{\gamma})^{m}} \\
\tau & =\tau_{y}+K \dot{\gamma}^{n} & & \\
\mu & =\mu_{\infty}+K \dot{\gamma}^{n-1} & &
\end{aligned}
$$

where $\tau_{\mathrm{y}}$ is yield stress $(\mathrm{Pa}), \eta_{\mathrm{B}}$ is the high shear limiting viscosity $(\mathrm{Pa} . \mathrm{s}), \gamma$ is the shear rate $\left(\mathrm{s}^{-1}\right), n$ is the flow index, $\mathrm{K}$ is the consistency index $\left(\mathrm{Pa} . \mathrm{s}^{n}\right), \mu_{\infty}$ is the infinite-rate apparent viscosity (Pa.s), $\mu_{0}$ is the zero-shear apparent viscosity 
(Pa.s), $\lambda$ is the time constant (s), and $m$ is the Cross rate constant, in equation (7) $T$ is temperature $(\mathrm{K}), \mu_{0}$ is a coefficient usually termed as frequency factor (pre-exponent coefficient), $E$ is the activation energy $\left(\mathrm{J}^{\mathrm{m}} \mathrm{mol}^{-1}\right)$ and $R$ is the universal gas constant $\left(8.314 \mathrm{~J} \cdot \mathrm{mol}^{-1} \mathrm{~K}^{-1}\right)$. Equations (1) to (6) are commonly used to model the shear stress $(\tau$ is the shear stress in $\mathrm{Pa}$ ) profile and viscosity ( $\mu$ is the viscosity in Pa.s) profile. Equation (7) shows the effect of temperature on apparent viscosity at a specified shear rate of fluid and can be described often by the Arrhenius relationship obtained from the Ostwald law model. Arrhenius type model equation can be used to describe the effect of temperature on apparent viscosity [23].

\section{Results and Discussion}

\subsection{Sludge characterization}

The samples of raw primary sludge, excess activated sludge and thickened excess activated sludge are characterized in Table 1 . The total solid content were $2.7 \%$ and $0.8 \%$ for raw primary, and excess activated sludge respectively. The sludge thickening process in the dissolved air flotation thickening unit resulted in an increase of the total solid content of the excess activated sludge from $0.8 \%$ to $3.7 \%$ solid for thickened excess activated sludge. $\mathrm{pH}$, total and volatile solid content and chemical oxygen demand measured for raw primary sludge, excess activated sludge and thickened excess activated sludge samples are also given in Table 1.

Table 1 Characterization of raw primary sludge, Excess activated sludge and thickened excess activated sludge

\begin{tabular}{|l|l|l|l|}
\hline Sludge sample & $\begin{array}{l}\text { Raw primary sludge } \\
(\text { RPS })\end{array}$ & $\begin{array}{l}\text { Excess activated } \\
\text { sludge } \\
(\text { EAS })\end{array}$ & $\begin{array}{l}\text { Thickened excess } \\
\text { activated sludge } \\
\text { (TEAS) }\end{array}$ \\
\hline Total solid content $(\%)$ & 2.7 & 0.8 & 3.7 \\
\hline Volatile solid content $(\%)$ & 2.4 & 0.6 & 3.0 \\
\hline Chemical oxygen demand (ppm) & 20100 & 1800 & 27500 \\
\hline pH & 6 & 7 & 7 \\
\hline Temperature $\left({ }^{\circ} \mathrm{C}\right)$ & 25 & 25 & 25 \\
\hline
\end{tabular}




\subsection{Effect of total solid concentration on thickened excess activated sludge rheology}

The effect of change in total solid concentration on thickened excess activated sludge rheological flow behavior was investigated for total solid concentrations of $3.7 \%, 3.1 \%, 2.6 \%, 2.1 \%, 1.3 \%$, and $0.9 \%$. The desired solid concentrations were achieved by using vacuum filtration technique and by dilution method using deionized water [5,

7, 18]. The rheological behavior of thickened excess activated sludge at the indicated solid concentrations was investigated by plotting shear stress-shear rate and viscosity-shear rate curves as shown in Fig. 1(a) and Fig. 1(b) respectively. The initial shear stress at zero shear-rate in the shear stress-shear rate plot was observed to increase with increasing total solid concentration as shown in Fig. 1(a). Similarly, viscosity was observed to increase with the increase of total solid concentration from $0.9 \%$ to $3.7 \%$ as shown in Fig. 1(b), due to the increase in solid content within the sludge sample. Furthermore, different rheological behaviour models were fitted to the shear stress-shear rate curve to obtain different rheological model parameters that are presented in Table 2. According to the Bingham pseudo-plastic model, the increase in total solid concentration resulted in the increase of yield stress as shown in Fig. 2(a). Similar trends were reported by Baroutian, et al. [7], Farno, et al. [8] and Spinosa, et al. [24]. According to Bingham pseudo-plastic model, the decrease in concentration from $3.7 \%$ to $3.1 \%$ resulted in drastic reduction of yield stress from $27.6 \mathrm{~Pa}$ to $11.0 \mathrm{~Pa}$, further reduction to $1.3 \mathrm{~Pa}$ was observed as solid content decreased to $1.3 \%$ as shown in Fig. 2(a). The viscosity-shear rate curves were also fitted to various rheological models, and the results are shown in Table 3. According to the Cross model, the zero-rate viscosity increased from 0.008Pa.s to 26.4Pa.s as total solid concentration increased from $0.9 \%$ to $3.7 \%$ as shown in Fig. 2(b). Similarly, the infinite-rate viscosity increased from 0.008Pa.s to 0.05Pa.s as the total solid content was reduced from $3.7 \%$ to $0.9 \%$ as shown Fig. 2(c). The flow index decreased from 1.38 to 0.25 with the increase in total solid concentration as shown in Fig. 2(d), indicating a change

from dilatant flow behavior to non-Newtonian nature. The increase in total solid concentration resulted in the increase of energy of cohesion and inter-particle interaction which lead to the change of flow consistency [21]. This is due to stronger network of sludge floc structure with the increase of solid concentration where colloidal, and hydrodynamic forces between sludge particles change [5, 7]. 
(a)

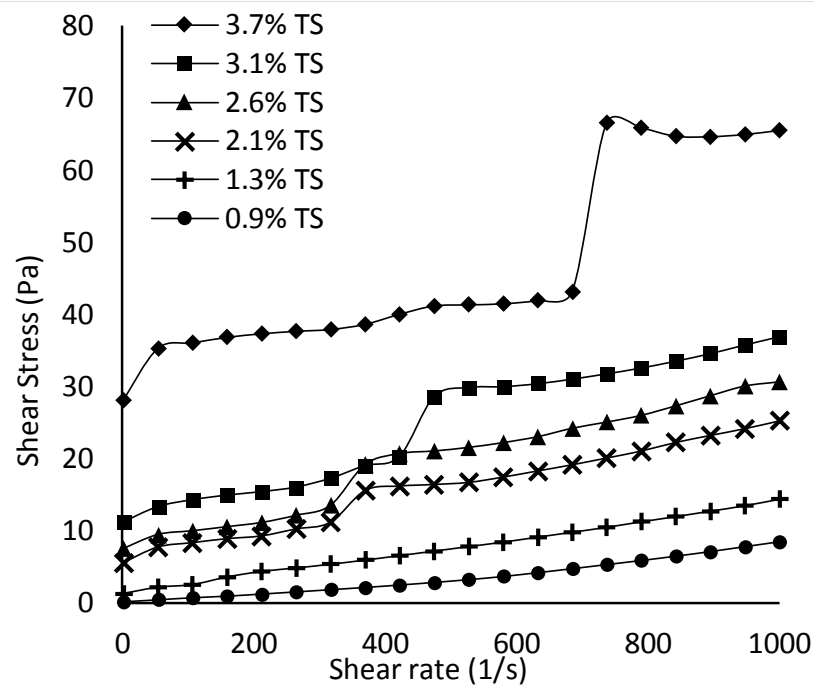

(b)

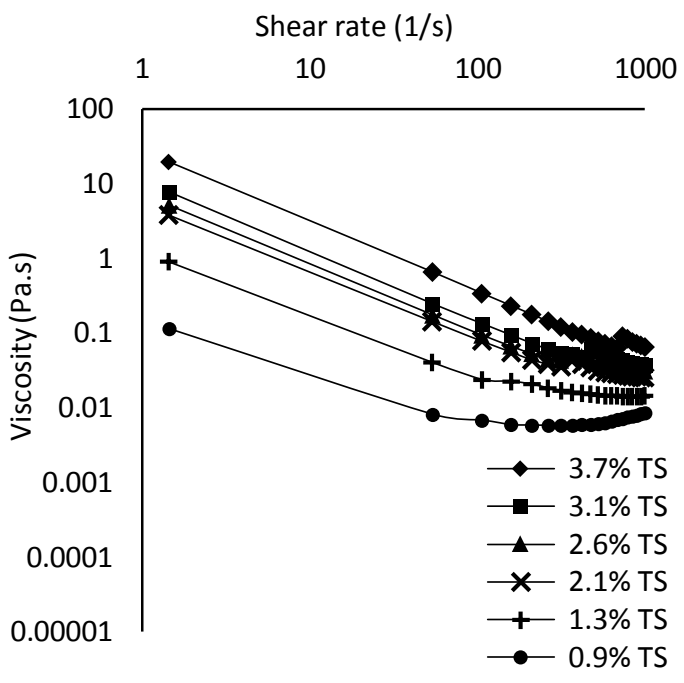

Fig. 1 (a) Shear stress-shear rate curves and (b) Viscosity-shear rate curves for different solid concentrations of thickened excess activated sludge at $\mathrm{T}=23^{\circ} \mathrm{C}$ and $\mathrm{pH}=7.0$ 
Table 2 Various rheological model parameters for varying total solid concentration of thickened excess activated sludge for different shear stress based rheological models

\begin{tabular}{|c|c|c|c|c|c|}
\hline Total Solid Concentration & Rheological Model & Yield Stress $(\mathrm{Pa})$ & Viscosity (Pa.s) & Flow Index & $\overline{\mathrm{R}^{2}}$ \\
\hline \multirow{3}{*}{$3.7 \%$} & Bingham & 27.6 & 0.04 & - & 0.90 \\
\hline & Power & - & 10.44 & 0.25 & 0.56 \\
\hline & Herschel-Bulkley & 33.4 & 0.0001 & 1.93 & 0.85 \\
\hline \multirow{3}{*}{$3.1 \%$} & Bingham & 11.0 & 0.03 & - & 0.94 \\
\hline & Power & - & 1.42 & 0.47 & 0.87 \\
\hline & Herschel-Bulkley & 10.2 & 0.05 & 0.91 & 0.94 \\
\hline \multirow{3}{*}{$2.6 \%$} & Bingham & 7.7 & 0.02 & - & 0.97 \\
\hline & Power & - & 0.78 & 0.53 & 0.93 \\
\hline & Herschel-Bulkley & 6.7 & 0.06 & 0.87 & 0.97 \\
\hline \multirow{3}{*}{$2.1 \%$} & Bingham & 6.2 & 0.02 & - & 0.98 \\
\hline & Power & - & 0.64 & 0.52 & 0.93 \\
\hline & Herschel-Bulkley & 5.5 & 0.04 & 0.89 & 0.98 \\
\hline \multirow{3}{*}{$1.3 \%$} & Bingham & 1.3 & 0.01 & - & 0.99 \\
\hline & Power & - & 0.05 & 0.81 & 0.99 \\
\hline & Herschel-Bulkley & 1.6 & 0.01 & 1.06 & 0.99 \\
\hline \multirow{3}{*}{$0.9 \%$} & Bingham & - & 0.01 & - & 0.97 \\
\hline & Power & - & - & 1.38 & 0.99 \\
\hline & Herschel-Bulkley & 0.4 & - & 1.58 & 0.99 \\
\hline
\end{tabular}


Table 3 Various rheological model parameters for varying total solid concentration of thickened excess activated sludge for different viscosity based rheological models

\begin{tabular}{|c|c|c|c|c|c|c|}
\hline $\begin{array}{l}\text { Total Solid } \\
\text { Concentration }\end{array}$ & $\begin{array}{l}\text { Rheological } \\
\text { Model }\end{array}$ & $\begin{array}{l}\text { Zero-rate } \\
\text { Viscosity (Pa.s) }\end{array}$ & $\begin{array}{l}\text { Infinite-rate } \\
\text { Viscosity (Pa.s) }\end{array}$ & $\begin{array}{l}\text { Consistency } \\
\text { Index (s) }\end{array}$ & $\begin{array}{l}\text { Flow } \\
\text { Index }\end{array}$ & $\mathrm{R}^{2}$ \\
\hline \multirow{3}{*}{$3.7 \%$} & Cross & 26.4 & 0.051 & 0.32 & 1.29 & 0.99 \\
\hline & Carreau & 21.4 & 0.051 & 0.28 & - & 0.99 \\
\hline & Sisko & - & 0.034 & 29.99 & - & 0.99 \\
\hline \multirow{3}{*}{$3.1 \%$} & Cross & 15.7 & 0.033 & 0.71 & 1.18 & 0.99 \\
\hline & Carreau & 9.8 & 0.033 & 0.49 & - & 0.99 \\
\hline & Sisko & - & 0.029 & 11.44 & - & 0.99 \\
\hline \multirow{3}{*}{$2.6 \%$} & Cross & 16.0 & 0.027 & 1.36 & 1.10 & 0.99 \\
\hline & Carreau & 7.6 & 0.027 & 0.70 & - & 0.99 \\
\hline & Sisko & - & 0.025 & 7.55 & - & 0.99 \\
\hline \multirow{3}{*}{$2.1 \%$} & Cross & 10.5 & 0.021 & 1.16 & 1.08 & 0.99 \\
\hline & Carreau & 5.3 & 0.021 & 0.63 & - & 0.99 \\
\hline & Sisko & - & 0.019 & 5.52 & 0.02 & 0.99 \\
\hline \multirow{3}{*}{$1.3 \%$} & Cross & 4.8 & 0.013 & 2.95 & 1.02 & 0.99 \\
\hline & Carreau & 1.6 & 0.012 & 1.03 & - & 0.99 \\
\hline & Sisko & - & 0.012 & 1.27 & 0.03 & 0.99 \\
\hline \multirow{3}{*}{$0.9 \%$} & Cross & 0.008 & 0.008 & 0.00 & - & 0.00 \\
\hline & Carreau & 0.007 & 0.007 & 0.00 & - & 0.00 \\
\hline & Sisko & - & 0.007 & 0.18 & - & 0.96 \\
\hline
\end{tabular}



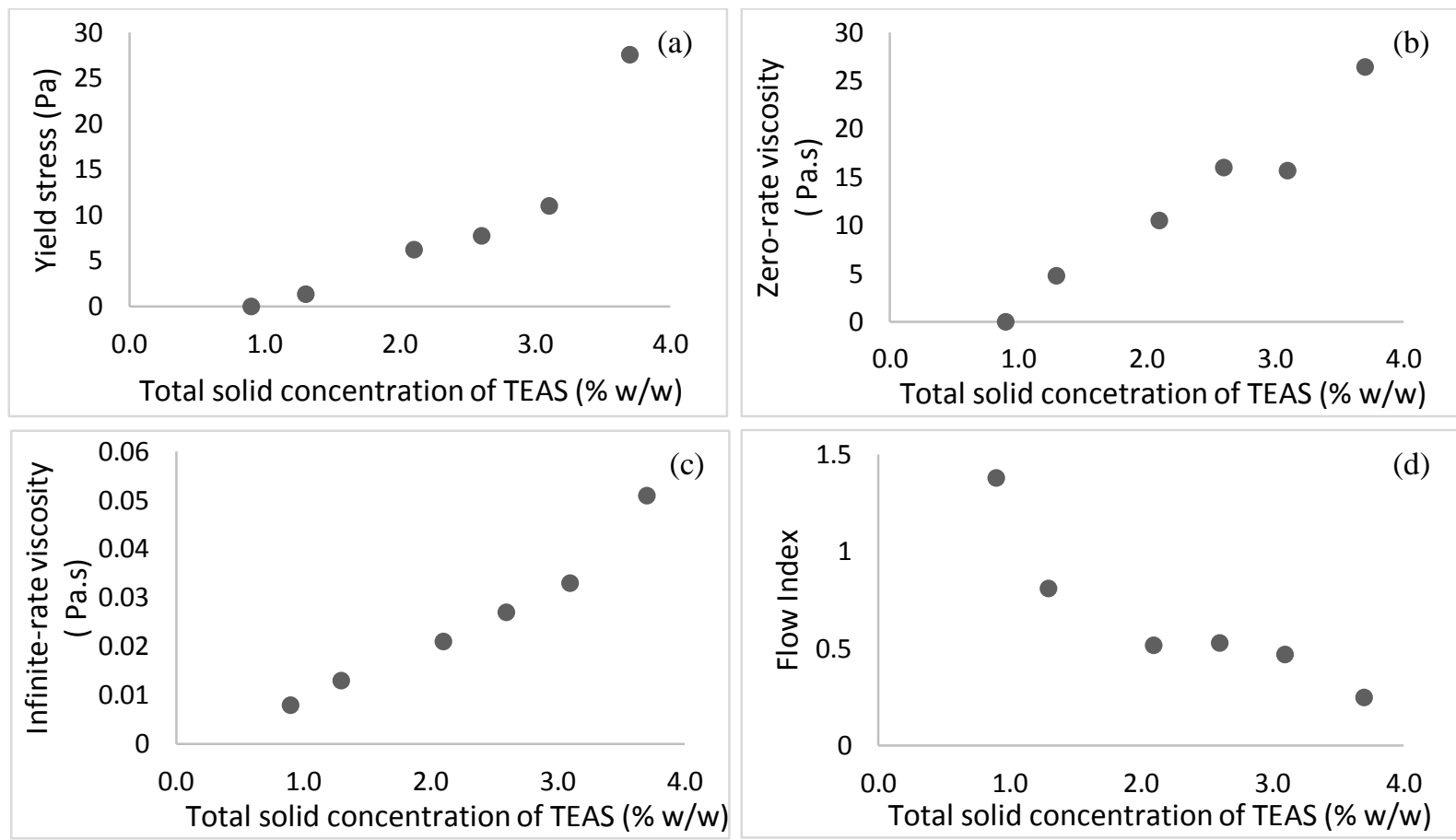

Fig. 2 Rheological model based parameters for varying total solid concentrations of thickened excess activated sludge (a) yield stress (Bingham), (b) zero-rate viscosity (Cross), (c) infinite-rate viscosity (Cross), and (d) flow index (Power)

\subsection{Effect of temperature on thickened excess activated sludge rheology}

The effect of temperature on rheological behavior of thickened excess activated sludge was studied at different temperatures of $23^{\circ} \mathrm{C}, 25^{\circ} \mathrm{C}, 30^{\circ} \mathrm{C}, 35^{\circ} \mathrm{C}, 45^{\circ} \mathrm{C}, 50^{\circ} \mathrm{C}$, and $55^{\circ} \mathrm{C}$ respectively. The desired temperature conditions were achieved by using Peltier Concentric Cylinder Temperature Control System, which is attached to the Discovery Hybrid Rheometer at typical heating rate of $10^{\circ} \mathrm{C} / \mathrm{min}$ [7]. The rheological behaviour of thickened excess activated sludge at different temperatures is presented as shear stress-shear rate curves and viscosity-shear rate curves as shown in Fig. 3(a) and Fig. 3(b) respectively. The shear stress at zero or infinite rates in the shear stress-shear rate plot was observed to decrease with increasing temperature as shown in Fig. 3(a). Similarly, viscosity was observed to decrease with increase in temperature as shown in Fig. 3(b), due to the weakening of inter-molecular cohesive forces within the activated sludge sample [25-27]. The experimental results show that there is a critical shear rate $\left(685 \mathrm{~s}^{-1}\right.$ at $23^{\circ} \mathrm{C}, 317 \mathrm{~s}^{-}$ ${ }^{1}$ at $25^{\circ} \mathrm{C}, 264 \mathrm{~s}^{-1}$ at $30^{\circ} \mathrm{C}, 369 \mathrm{~s}^{-1}$ at $35^{\circ} \mathrm{C}$ and $422 \mathrm{~s}^{-1}$ at $50^{\circ} \mathrm{C}$ ) where shear stress increases suddenly to a much higher level for a given temperature due to changes in the floc-size-density-structure of the thickened activated sludge samples subjected to shearing. This critical shear rate shifted back to lower values between temperatures of $23^{\circ} \mathrm{C}$ and 
$30^{\circ} \mathrm{C}$ and increased again between temperatures of $35^{\circ} \mathrm{C}$ and $50^{\circ} \mathrm{C}$ as shown in Fig. 3(a). This critical region helps to decide the shear rate that pumps, fluid movers and agitators should deliver to thickened excess activated sludge at a given temperature to minimize power consumption and achieve smooth flow of the sludge. Furthermore, different rheological models were fitted to the shear stress-shear rate curves and the rheological model parameters obtained from the model fitting are tabulated in Table 4. According to the Bingham pseudo-plastic model, the increase in temperature resulted in decrease of yield stress as shown in Fig. 4(a). Similar trends were reported by many authors such as Eshtiaghi, et al. [11], Farno, et al. [8], Appels, et al. [25], Paul, et al. [26], Hasar, et al. [12], and Manoliadis, et al. [27] for other sludge systems. Bingham pseudo-plastic model fitting resulted in the reduction of yield stress from 20.1Pa to $8.3 \mathrm{~Pa}$ for the increase in temperature from $25^{\circ} \mathrm{C}$ to $55^{\circ} \mathrm{C}$ as shown in Fig. 4(a). The viscosity shear rate curves were also fitted to various rheological models and model parameters are reported in Table 5. According to the Cross model, the zero-rate viscosity showed a decreasing trend from $33 \mathrm{kPa}$.s to $4.4 \mathrm{~Pa} . \mathrm{s}$ for temperature increasing from $25^{\circ} \mathrm{C}$ to $55^{\circ} \mathrm{C}$ as shown in Fig. 4(b). In contrast, the infinite-rate viscosity showed an increasing trend from 0.021Pa.s to $0.031 \mathrm{~Pa}$.s as the temperature was increased from $25^{\circ} \mathrm{C}$ to $50^{\circ} \mathrm{C}$ and it decreased to $0.024 \mathrm{~Pa}$.s for $55^{\circ} \mathrm{C}$ as shown Fig. 4(c). The decrease in infinite-rate viscosity is due to some restructuring in the floc network which resulted in the weakening of the network strength and a corresponding decrease in infinite rate viscosity. The flow index was observed to increase from 0.27 to 0.43 with the increase of temperature from $25^{\circ} \mathrm{C}$ to $55^{\circ} \mathrm{C}$ as shown in Fig. $4(\mathrm{~d})$, indicating thickened excess activated sludge showed strictly non-Newtonian pseudo-plastic behaviour in the temperature range investigated in this study. 
(a)

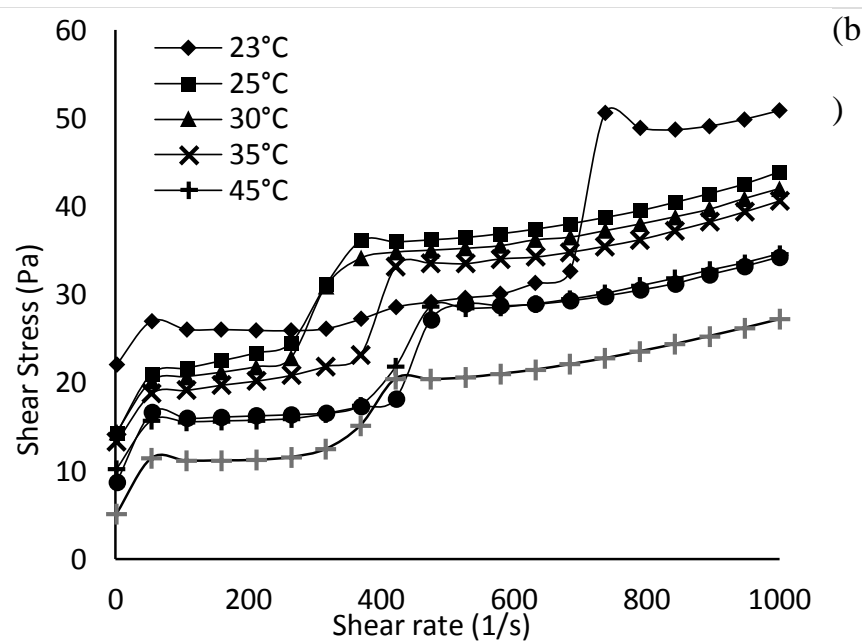

(b

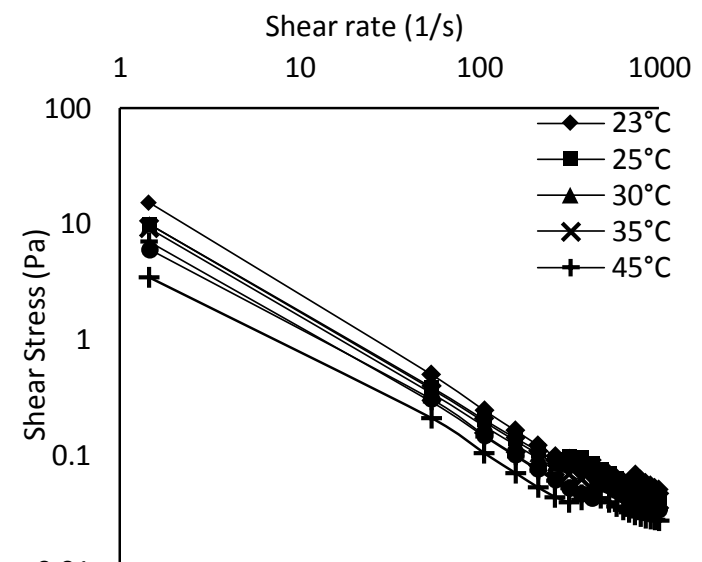

Fig. 3 (a) Shear stress-shear rate curves and (b) Viscosity-shear rate curves for different temperatures of thickened excess activated sludge with $\mathrm{TS}=3.5 \% \mathrm{w} / \mathrm{w}$ and $\mathrm{pH}=7.0$ 
Table 4 Various rheological model parameters for varying thickened excess activated sludge temperature for different shear stress based rheological models

\begin{tabular}{|c|c|c|c|c|c|}
\hline $\begin{array}{l}\text { Temperature } \\
\left({ }^{\circ} \mathrm{C}\right)\end{array}$ & Rheological Model & Yield Stress $(\mathrm{Pa})$ & Viscosity (Pa.s) & Flow Index & $\mathrm{R}^{2}$ \\
\hline \multirow{3}{*}{25} & Bingham & 20.1 & 0.03 & - & 0.88 \\
\hline & Power & - & 6.6 & 0.27 & 0.90 \\
\hline & Herschel-Bulkley & 12.5 & 0.94 & 0.51 & 0.94 \\
\hline \multirow{3}{*}{30} & Bingham & 19.3 & 0.03 & - & 0.88 \\
\hline & Power & - & 6.36 & 0.27 & 0.88 \\
\hline & Herschel-Bulkley & 12.6 & 0.77 & 0.53 & 0.93 \\
\hline \multirow{3}{*}{35} & Bingham & 16.2 & 0.03 & - & 0.91 \\
\hline & Power & - & 4.17 & 0.32 & 0.85 \\
\hline & Herschel-Bulkley & 13.0 & 0.21 & 0.71 & 0.93 \\
\hline \multirow{3}{*}{45} & Bingham & 11.9 & 0.02 & - & 0.92 \\
\hline & Power & - & 2.21 & 0.39 & 0.84 \\
\hline & Herschel-Bulkley & 10.8 & 0.06 & 0.86 & 0.92 \\
\hline \multirow{3}{*}{50} & Bingham & 11.9 & 0.02 & - & 0.90 \\
\hline & Power & - & 2.37 & 0.38 & 0.83 \\
\hline & Herschel-Bulkley & 10.6 & 0.07 & 0.84 & 0.90 \\
\hline \multirow{3}{*}{55} & Bingham & 8.3 & 0.02 & - & 0.93 \\
\hline & Power & - & 1.31 & 0.43 & 0.91 \\
\hline & Herschel-Bulkley & 5.9 & 0.15 & 0.72 & 0.94 \\
\hline
\end{tabular}


Table 5 Various rheological model parameters for varying thickened excess activated sludge temperature for different viscosity based rheological models

\begin{tabular}{|c|c|c|c|c|c|c|}
\hline $\begin{array}{l}\text { Temperature } \\
\left({ }^{\circ} \mathrm{C}\right)\end{array}$ & $\begin{array}{l}\text { Rheological } \\
\text { Model }\end{array}$ & $\begin{array}{l}\text { Zero-rate } \\
\text { Viscosity (Pa.s) }\end{array}$ & $\begin{array}{l}\text { Infinite-rate } \\
\text { Viscosity (Pa.s) }\end{array}$ & $\begin{array}{l}\text { Consistency } \\
\text { Index (s) }\end{array}$ & $\begin{array}{l}\text { Flow } \\
\text { Index }\end{array}$ & $\mathrm{R}^{2}$ \\
\hline \multirow{3}{*}{25} & Cross & $33.4 \times 10^{3}$ & 0.021 & $52.7 \mathrm{E} 3$ & 0.91 & 0.96 \\
\hline & Carreau & 660.0 & 0.020 & 70.92 & - & 0.96 \\
\hline & Sisko & - & 0.020 & 13.59 & 0.09 & 0.99 \\
\hline \multirow{3}{*}{30} & Cross & $46.0 \times 10^{3}$ & 0.021 & $6.5 \mathrm{E} 3$ & 0.92 & 0.99 \\
\hline & Carreau & 809.3 & 0.021 & 82.39 & - & 0.99 \\
\hline & Sisko & - & 0.021 & 13.69 & 0.08 & 0.99 \\
\hline \multirow{3}{*}{35} & Cross & 32.8 & 0.028 & 1.72 & 1.03 & 0.99 \\
\hline & Carreau & 13.7 & 0.028 & 0.75 & - & 0.99 \\
\hline & Sisko & - & 0.024 & 13.22 & 0.04 & 0.99 \\
\hline \multirow{3}{*}{45} & Cross & 9.8 & 0.032 & 0.31 & 1.28 & 0.99 \\
\hline & Carreau & 7.7 & 0.031 & 0.27 & - & 0.99 \\
\hline & Sisko & - & 0.023 & 10.51 & 0.03 & 0.99 \\
\hline \multirow{3}{*}{50} & Cross & 7.3 & 0.031 & 0.21 & 1.34 & 0.99 \\
\hline & Carreau & 5.7 & 0.031 & 0.20 & - & 0.99 \\
\hline & Sisko & - & 0.020 & 9.06 & 0.07 & 0.99 \\
\hline \multirow{3}{*}{55} & Cross & 4.4 & 0.024 & 23.1E3 & 1.25 & 0.99 \\
\hline & Carreau & 3.7 & 0.024 & 0.22 & - & 0.99 \\
\hline & Sisko & - & 0.016 & 5.06 & 0.12 & 0.99 \\
\hline
\end{tabular}



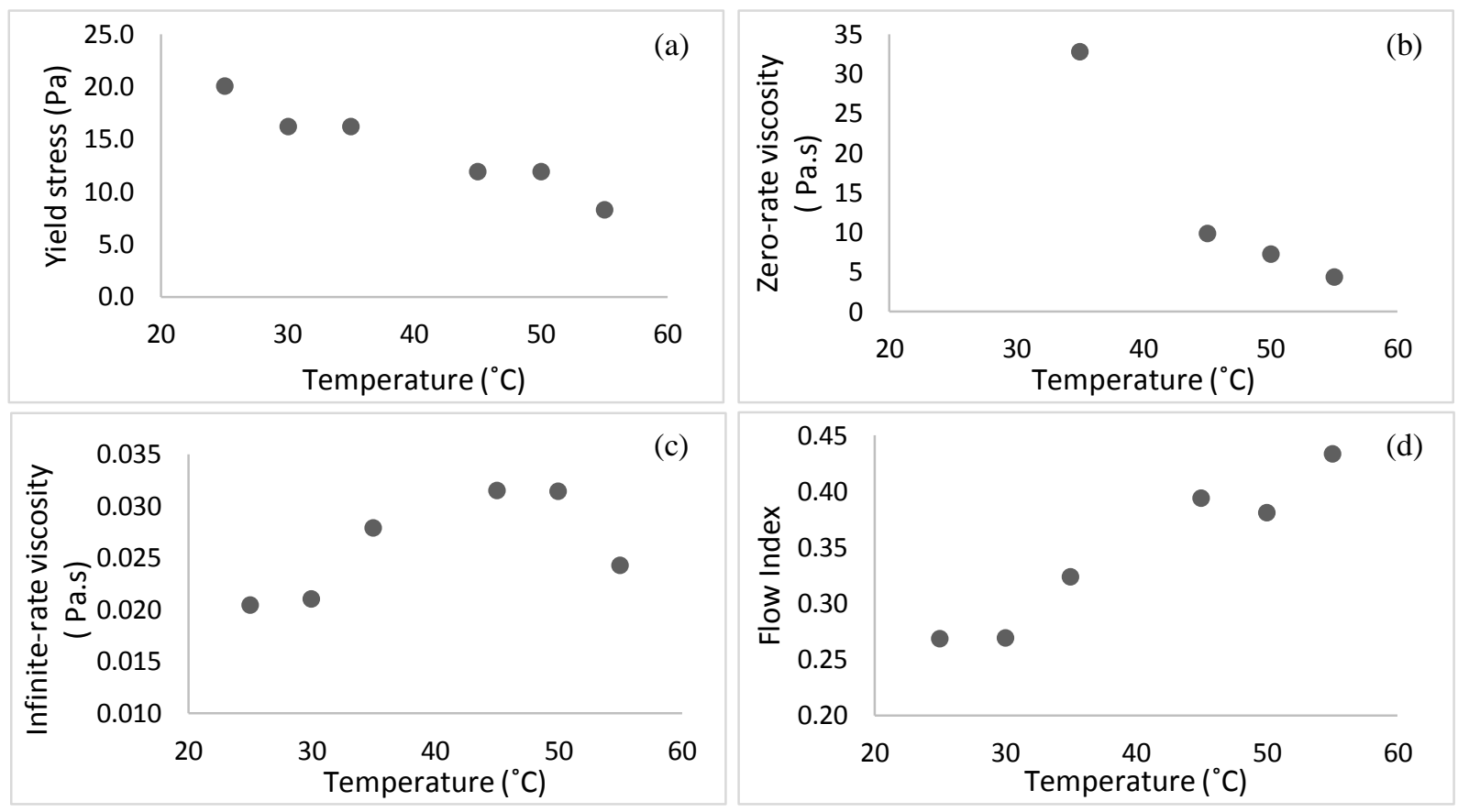

Fig. 4 Rheological model based parameters for varying temperature of thickened excess activated sludge (a) yield stress (Bingham), (b) zero-rate viscosity (Cross), (c) infinite-rate viscosity (Cross), and (d) flow index (Power)

\subsection{The relationship between activation energy and apparent viscosity of TEAS due to change in temperature}

Activation energy-shear rate relationship for thickened excess activated sludge for a temperature range of $25^{\circ} \mathrm{C}$ to $55^{\circ} \mathrm{C}$ and shear rate range of $1 \mathrm{~s}^{-1}$ to $1000 \mathrm{~s}^{-1}$ was developed by using Arrhenius type of equation (Equation 7). The experimental work conducted on the effect of temperature on the rheological behaviour of thickened excess activated sludge was used for the development of Arrhenius type relationship. The plot of the natural logarithm of the apparent viscosity in Pascal seconds $(\eta)$ (ordinate) versus inverse of temperature in Kelvin (1/T) (abscissa) at a particular shear rate as shown in Fig. 5 was used to determine the activation energy (slope) and frequency factor (intercept). The activation energy and the frequency factor show a consistent relationship for varying shear rate as shown in Fig. 6. Higher activation energy is associated with increased resistance to flow before the normal flow is achieved and the molecular (floc particle) activity for such a condition is low as it can be observed from the plot of frequency factor. Higher activation energy value corresponds to lower frequency or pre-exponent factor as presented in Fig. 6. The activation energy required at lower shear rate $\left(1.45 \mathrm{~s}^{-1}\right)$ is very high, $25.1 \mathrm{KJ}_{\mathrm{mol}}{ }^{-1}$ and it drastically decreased to a 
relatively lower value of $13.8 \mathrm{KJ}_{\mathrm{mol}}{ }^{-1}$ at shear rate of $54 \mathrm{~s}^{-1}$. It increased to a higher value of $24.8 \mathrm{KJ} . \mathrm{mol}^{-1}$ between shear rates of $54 \mathrm{~s}^{-1}$ to $369 \mathrm{~s}^{-1}$; however, further increase in shear rate to $527 \mathrm{~s}^{-1}$ resulted is a rapid decrease of the activation energy down to $13.1 \mathrm{KJ} . \mathrm{mol}^{-1}$. The activation energy was observed to decrease very slightly down to $11.3 \mathrm{KJ}_{\mathrm{mol}}{ }^{-1}$ in the shear rate range of $527 \mathrm{~s}^{-1}$ to $1000 \mathrm{~s}^{-1}$. In general, in the rheological investigation of thickened excess activated sludge, the activation energy indirectly shows the strength of the inter-particle forces that keep the floc network together. Increase in activation energy shows higher resistance to flow or greater floc network strength. On the other hand, the frequency factor shows the distribution of the flocs, hence higher activation energy resulting in restricted flow relates to low frequency factor and vice versa. The trend in the frequency factor corresponds well to the described activation energy profile (Fig. 6).

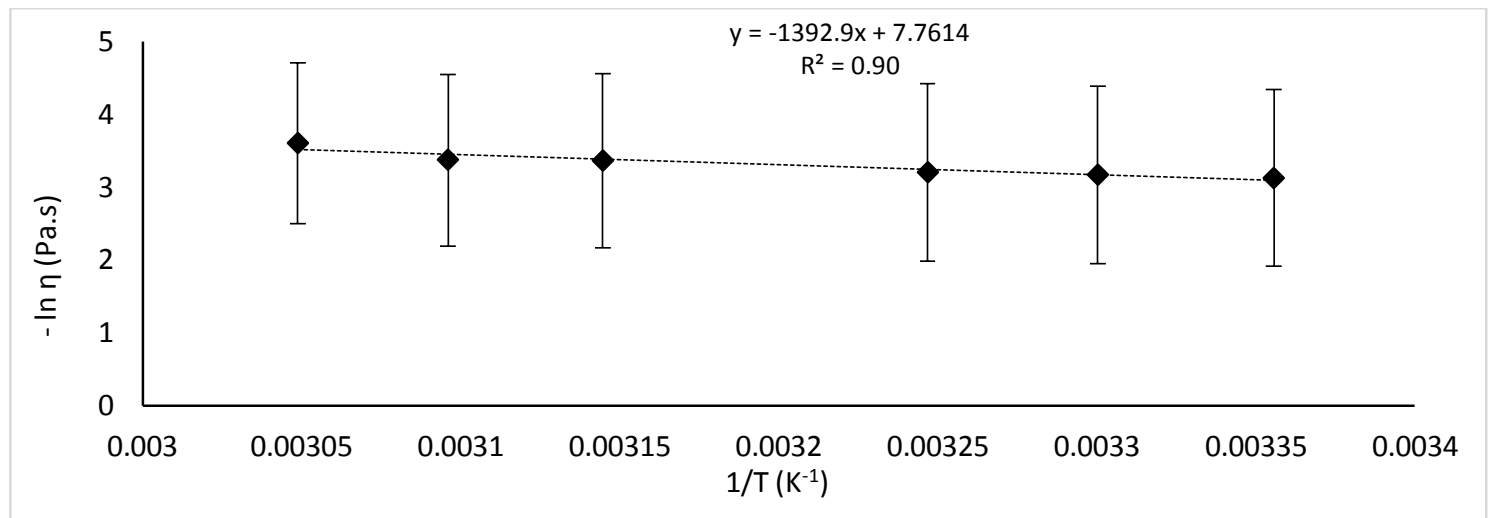

Fig. 5 Apparent viscosity of thickened excess activated sludge versus $(1 / T)$ plot for the determination of activation energy 


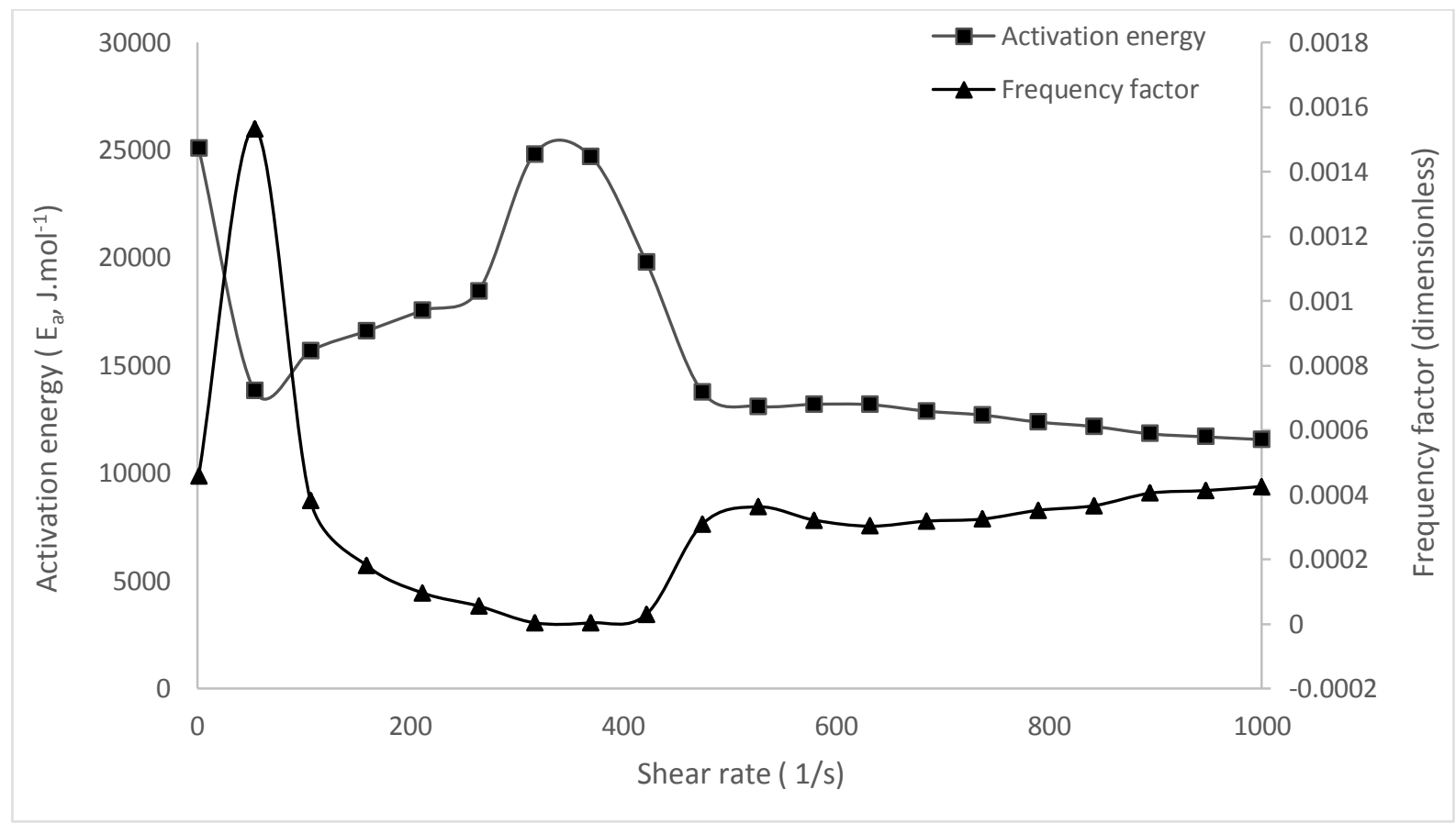

Fig. 6 Activation energy (Ea, J/mol) and frequency factor (dimensionless) versus shear rate plot for temperature range of $\left(23^{\circ} \mathrm{C}-55^{\circ} \mathrm{C}\right)$

\subsection{Effect of $\mathrm{pH}$ on thickened excess activated sludge rheology}

In this study, the effect of $\mathrm{pH}$ range was investigated for the range of 3.6 to 10.0 so that the rheological properties of thickened excess activated sludge can be established in both acidic and alkaline regions. The $\mathrm{pH}$ of thickened excess activated sludge was adjusted by the addition of hydrochloric acid and sodium hydroxide [9]. Experimental results show that $\mathrm{pH}$ significantly affects the shear stress-shear rate and viscosity shear rate profile of thickened excess activated sludge as shown in Fig. 7(a) and Fig. 7(b) respectively. The shear stress requirement at a given shear rate was observed to increase with increasing $\mathrm{pH}$ as shown in Fig. 7(a). The trend observed in the shear stress-shear rate profile is due to the flocculation effect and formation of stronger floc networks with the change in the charge and colloidal chemistry of the sludge floc particles [14]. Viscosity, on the other hand, showed a different trend from that shown in Fig. 7(b). Sludge particle surfaces tend to become more negatively charged when the pH increases above the isoelectric point. Hence, the isoelectric point of bacteria being between $\mathrm{pH}$ of 2.0 and 4.0 [28], $\mathrm{pH}$ of 3.6, in this study, falls within the isoelectric range; Therefore, at a higher $\mathrm{pH}$ values, the particle surfaces of thickened excess activated sludge will be more negatively charged resulting in repulsion and expansion effects. This condition is 
important as the extent of compaction of particle structure plays a role in the fluid flow and deformation properties of the sludge and will have an effect on resistance to flow due to the size of exposed cross-sectional area of solids [9]. Different rheological models were also fitted to the shear stress-shear rate and viscosity-shear rate curves the same way as the other parameters discussed in the above sections as shown in Table 6 and Table 7. Based on the Bingham model, yield stress was observed to increase from $6.0 \mathrm{~Pa}$ to $8.3 \mathrm{~Pa}$ for $\mathrm{pH}$ of 3.6 to 5.4 , and it further increased from 6.6Pa to 8.3Pa for a $\mathrm{pH}$ change from 7.0 to 10.0 as shown in Fig. 8(a). According to the Cross model, the zero-rate viscosity was mostly constant around 3.9Pa.s to 4.9Pa.s for all the pH conditions considered in this study as shown in Fig. 8(b). Furthermore, the infinite-rate viscosity decreased from 0.02Pa.s to 0.016Pa.s as shown in Fig. 8(c) and the flow index showed non-Newtonian behaviour for the whole $\mathrm{pH}$ range of 3.6 to 10.0 Fig. 8(d). The number of negative surface charges were observed to decrease under acid condition because of the neutralization effect on the negative functional groups located on the surface of extracellular polymeric substances (EPS) of the sludge particle.

(a)

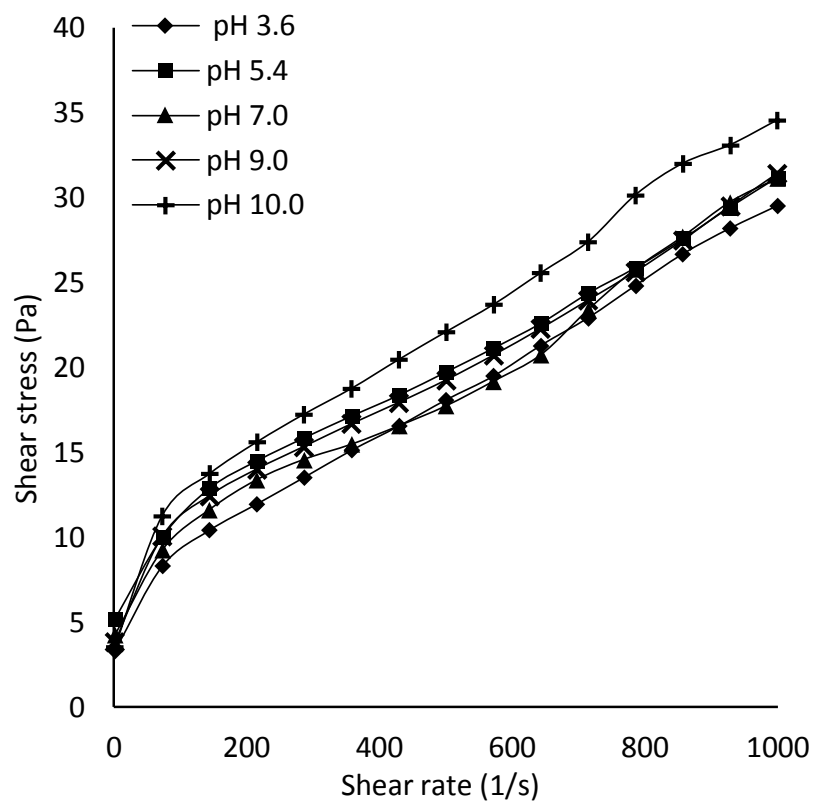

(b)

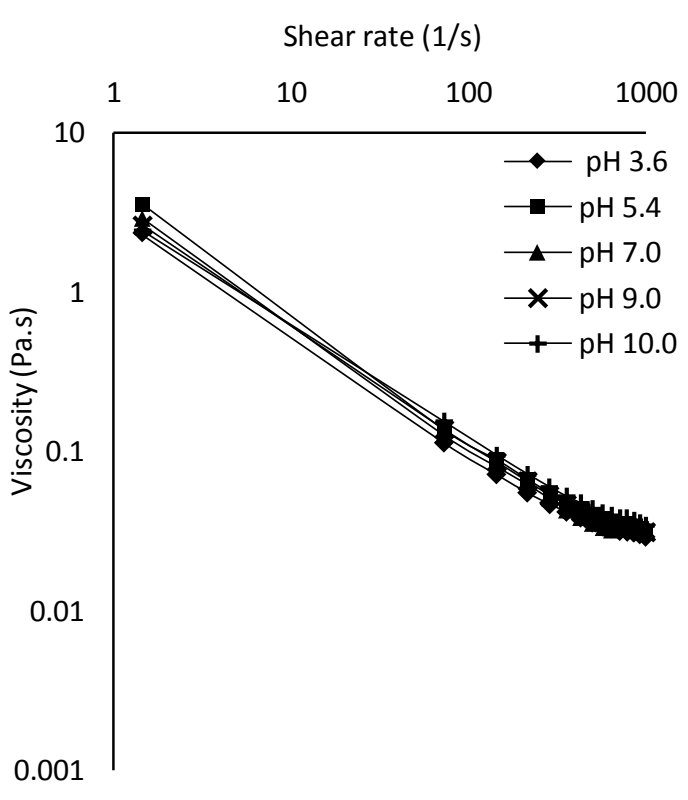

Fig. 7 (a) shear stress-shear rate curves and (b) viscosity-shear rate curves for thickened excess activated sludge at different $\mathrm{pH}$ condition at $\mathrm{T}=23^{\circ} \mathrm{C}$ and $\mathrm{TS}=3.5 \% \mathrm{w} / \mathrm{w}$ 
Table 6 Various rheological model parameters for varying $\mathrm{pH}$ of thickened excess activated sludge for different shear stress based rheological models

\begin{tabular}{|c|c|c|c|c|c|}
\hline $\mathrm{pH}$ & Model & Yield Stress $(\mathrm{Pa})$ & Viscosity (Pa.s) & Flow Index & $\mathrm{R}^{2}$ \\
\hline \multirow{3}{*}{3.6} & Bingham & 6.0 & 0.024 & - & 0.99 \\
\hline & Power & - & 0.6 & 0.57 & 0.98 \\
\hline & $\begin{array}{l}\text { Herschel- } \\
\text { Bulkley }\end{array}$ & 4.2 & 0.107 & 0.79 & 0.99 \\
\hline \multirow{3}{*}{5.4} & Bingham & 8.3 & 0.023 & - & 0.98 \\
\hline & Power & - & 1.19 & 0.46 & 0.96 \\
\hline & $\begin{array}{l}\text { Herschel- } \\
\text { Bulkley }\end{array}$ & 5.9 & 0.15 & 0.74 & 0.99 \\
\hline \multirow{3}{*}{7.0} & Bingham & 6.6 & 0.024 & - & 0.98 \\
\hline & Power & - & 0.63 & 0.55 & 0.94 \\
\hline & $\begin{array}{l}\text { Herschel- } \\
\text { Bulkley }\end{array}$ & 6.1 & 0.04 & 0.93 & 0.98 \\
\hline \multirow{3}{*}{9.0} & Bingham & 7.5 & 0.024 & - & 0.97 \\
\hline & Power & - & 0.97 & 0.49 & 0.96 \\
\hline & $\begin{array}{l}\text { Herschel- } \\
\text { Bulkley }\end{array}$ & 5.0 & 0.17 & 0.72 & 0.99 \\
\hline \multirow{3}{*}{10.0} & Bingham & 8.3 & 0.027 & - & 0.97 \\
\hline & Power & - & 1.03 & 0.50 & 0.98 \\
\hline & $\begin{array}{l}\text { Herschel- } \\
\text { Bulkley }\end{array}$ & 4.4 & 0.29 & 0.67 & 0.99 \\
\hline
\end{tabular}


Table 7 Various rheological model parameters for varying $\mathrm{pH}$ of thickened excess activated sludge for different viscosity based rheological models

\begin{tabular}{|c|c|c|c|c|c|c|}
\hline $\mathrm{pH}$ & Model & $\begin{array}{l}\text { Zero-rate } \\
\text { (Pa.s) }\end{array}$ & $\begin{array}{l}\text { Infinite-rate Viscosity } \\
\text { (Pa.s) }\end{array}$ & $\begin{array}{l}\text { Consistency Index } \\
\text { (s) }\end{array}$ & $\begin{array}{l}\text { Flow } \\
\text { Index }\end{array}$ & $\mathrm{R}^{2}$ \\
\hline \multirow{3}{*}{3.6} & Cross & 4.9 & 0.022 & 0.79 & 0.97 & 1.00 \\
\hline & Carreau & 660.0 & 0.020 & 70.92 & - & 0.96 \\
\hline & Sisko & - & 0.020 & 13.59 & 0.09 & 1.00 \\
\hline \multirow{3}{*}{5.4} & Cross & 22.4 & 0.018 & 4.94 & 0.90 & 1.00 \\
\hline & Carreau & 6.6 & 0.018 & 1.19 & - & 1.00 \\
\hline & Sisko & - & 0.017 & 4.92 & 0.14 & 1.00 \\
\hline \multirow{3}{*}{7.0} & Cross & 4.9 & 0.023 & 0.49 & 1.06 & 1.00 \\
\hline & Carreau & 3.3 & 0.023 & 0.36 & - & 1.00 \\
\hline & Sisko & - & 0.018 & 4.04 & 0.15 & 1.00 \\
\hline \multirow{3}{*}{9.0} & Cross & 4.8 & 0.021 & 0.55 & 0.99 & 0.99 \\
\hline & Carreau & 3.0 & 0.021 & 0.38 & - & 1.00 \\
\hline & Sisko & - & 0.015 & 3.59 & 0.20 & 1.00 \\
\hline \multirow{3}{*}{10.0} & Cross & 3.9 & 0.024 & 0.41 & 0.98 & 1.00 \\
\hline & Carreau & 2.7 & 0.024 & 0.31 & - & 1.00 \\
\hline & Sisko & - & 0.016 & 3.26 & 0.25 & 1.00 \\
\hline
\end{tabular}




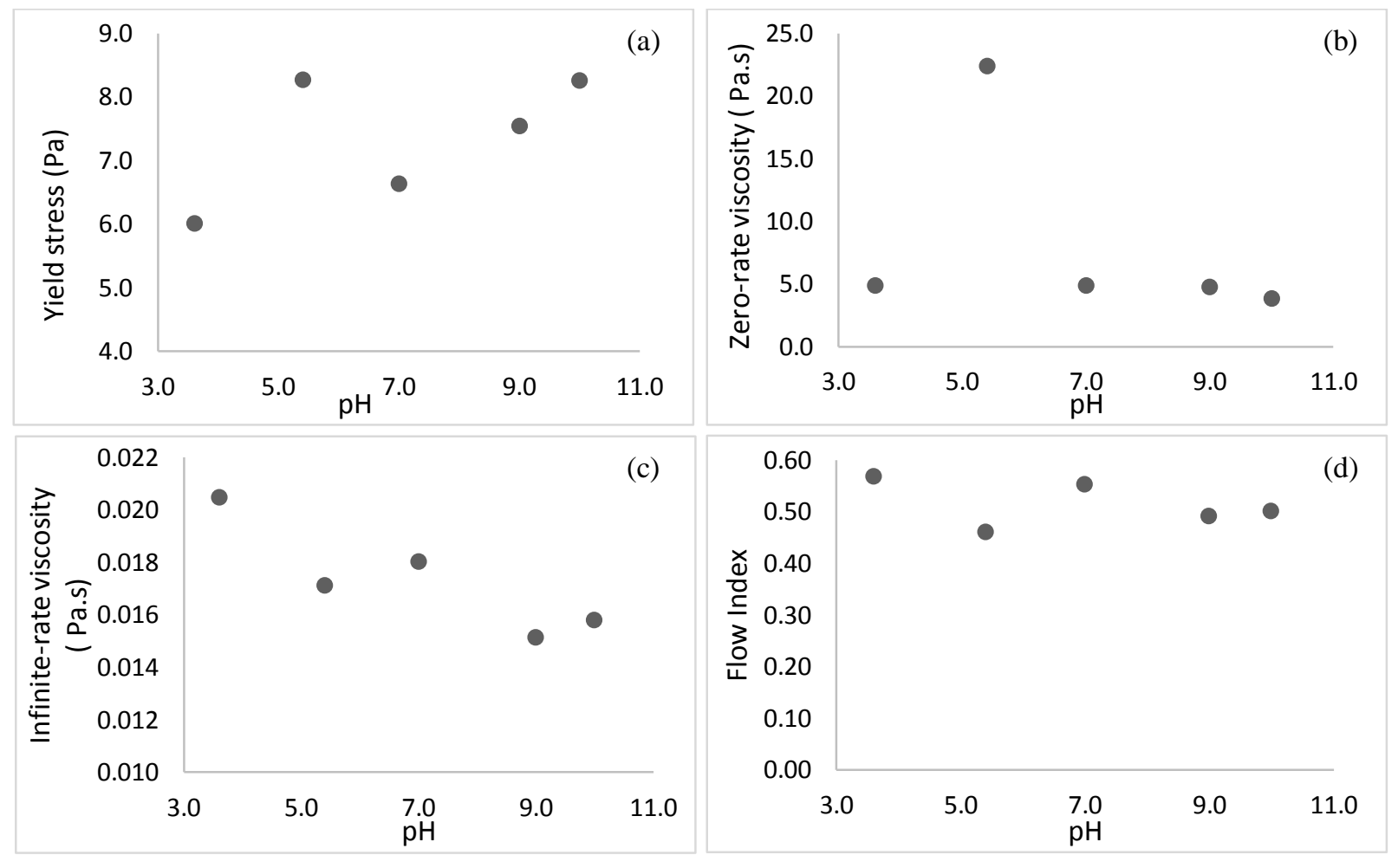

Fig. 8 Rheological model based parameters for varying $\mathrm{pH}$ of thickened excess activated sludge (a) yield stress (Bingham), (b) zero-rate viscosity (Cross), (c) infinite-rate viscosity (Sisko), and (d) flow index (Power)

\subsection{Comparison of rheological behaviour between raw primary, excess activated, thickened excess activated sludge, and mixed sludge.}

The rheological behaviours of different sludge types such as raw primary sludge (RPS), excess activated sludge (EAS), thickened excess activated sludge (TEAS), and mixture of PRS and TEAS are presented in Fig. 9. The shear stressshear rate plot for thickened excess activated sludge ranges from $28.2 \mathrm{~Pa}$ for zero shear rate to $65.56 \mathrm{~Pa}$ for $1000 \mathrm{~s}^{-1}$ shear rate. The shear force requirement of TEAS to achieve normal flow is much higher than RPS and EAS. This is associated with the presence of significant amount of bio-polymeric material that exhibited colloidal property and greater total solid concentration. Moreover, the shear stress shows a sudden jump from 43.2Pa to 66.6Pa between shear rate ranges of $680 \mathrm{~s}^{-1}$ to $740 \mathrm{~s}^{-1}$. This is because of significant change in floc structure and size due to special shearing effect [29]. Rheological model parameters were generated from the shear stress-shear rate curves as shown in Table 8. Yield stress for thickened excess activated sludge was calculated to be 30.1Pa, 33.0Pa and 25.1Pa according to Casson, Bingham, and Herschel-Bulkley models respectively as shown in Table 8. Mixture of raw primary sludge 22 
and thickened excess activated sludge showed intermediate rheological behaviour but with significantly reduced yield stress of 2.9Pa and viscosity of 0.05Pa.s. The reduction in yield stress and viscosity, as shown in Fig. 9(a) and Fig. 9(b), in the mixed sludge has significant implications on mixing hydrodynamics, mass transfer and power requirement in the anaerobic digester's performance. Raw primary sludge exhibited lower yield stress of 2.6Pa and excess activated sludge directly coming from the activated sludge treatment process has extremely low yield stress of $0.2 \mathrm{~Pa}$ and behaves like a Newtonian fluid (Fig. 9) as the total solid content is very low (0.8\%). This observation is also supported by the results for flow index as shown in Table 8 . In addition, mixed sludge rheological property is largely affected by the concentration of thickened excess activated sludge and both show non-Newtonian pseudoplastic $(\mathrm{K}<1)$ behaviour while raw primary and excess activated sludge show slightly dilatant behaviour.

(a)

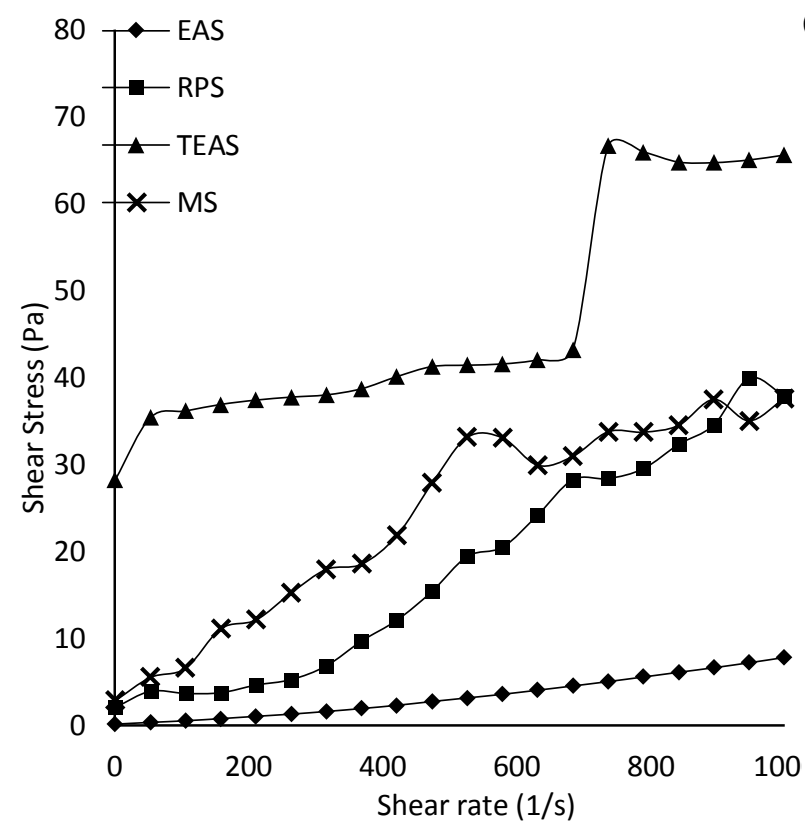

(b)

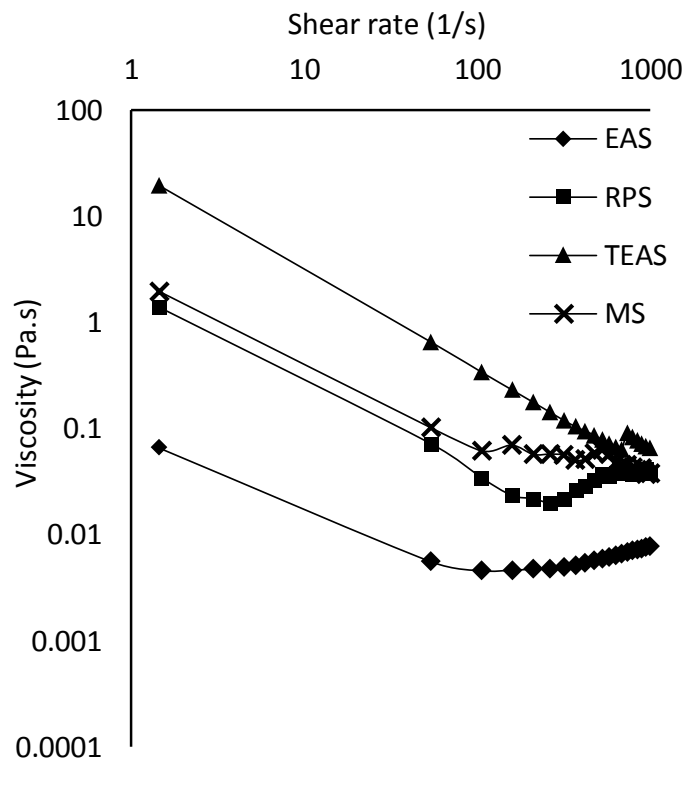

Fig. 9 (a) Shear stress-shear rate curves and (b) Viscosity-shear rate curves for different sludge types, EAS: $\mathrm{TS}=0.8 \% \mathrm{w} / \mathrm{w}, \mathrm{T}=25^{\circ} \mathrm{C} \& \mathrm{pH}=7, \mathrm{RPS}: \mathrm{TS}=2.7 \% \mathrm{w} / \mathrm{w}, \mathrm{T}=25^{\circ} \mathrm{C} \& \mathrm{pH}=6$, TEAS: $\mathrm{TS}=3.7 \% \mathrm{w} / \mathrm{w}, \mathrm{T}=25^{\circ} \mathrm{C} \& \mathrm{pH}=7$, and MS: $\mathrm{TS}=3.0 \% \mathrm{w} / \mathrm{w}, \mathrm{T}=25^{\circ} \mathrm{C} \& \mathrm{pH}=7$ 
Table 8 Yield stress, viscosity and flow index based on different rheological models for different sludge types

\begin{tabular}{|c|c|c|c|c|c|}
\hline Sludge Type & Rheological Model & $\begin{array}{ll}\text { Yield } & \text { Stress } \\
(\mathrm{Pa}) & \end{array}$ & $\begin{array}{l}\text { Viscosity } \\
\text { (Pa.s) }\end{array}$ & $\begin{array}{l}\text { Flow } \\
\text { Index }\end{array}$ & $\mathrm{R}^{2}$ \\
\hline \multirow{3}{*}{$\begin{array}{l}\text { Thickened Excess } \\
\text { Sludge }\end{array}$} & Bingham & 33 & 0.02 & - & 0.82 \\
\hline & Power & - & 26.6 & 0.1 & 0.94 \\
\hline & Herschel-Bulkley & 25.1 & 3.2 & 0.3 & 0.96 \\
\hline \multirow{3}{*}{ Raw Primary Sludge } & Bingham & - & 0.04 & - & 0.91 \\
\hline & Power & - & $7.5 \mathrm{E}-04$ & 1.6 & 0.97 \\
\hline & Herschel-Bulkley & 2.6 & $3.5 \mathrm{E}-05$ & 2.1 & 0.99 \\
\hline \multirow{3}{*}{ Mixture of RPS and TEAS } & Bingham & 2.9 & 0.05 & - & 0.92 \\
\hline & Power & - & 0.18 & 0.6 & 0.95 \\
\hline & Herschel-Bulkley & 1.9 & 0.09 & 0.6 & 0.95 \\
\hline \multirow{3}{*}{ Excess Activated Sludge } & Bingham & 0 & $6.5 \mathrm{E}-03$ & - & 0.98 \\
\hline & Power & - & $8.1 \mathrm{E}-03$ & 1.3 & 0.99 \\
\hline & Herschel-Bulkley & 0.2 & 3.4E-04 & 1.4 & 0.99 \\
\hline
\end{tabular}

\subsection{Polymer dose optimization and effects on excess activated sludge thickening}

Polymer consumption optimization in dissolved air flotation thickeners is crucial to minimize operational cost of wastewater treatment plants. Experimental polymer consumption optimization was conducted in this study using a combination of jar test and rheological flow investigation for different polymer doses (expressed in kilogram of polymer per ton of dried solids) of $1.0 \mathrm{~kg} / \mathrm{ton}$ DS, $1.3 \mathrm{~kg} / \mathrm{ton}$ DS, $1.5 \mathrm{~kg} / \mathrm{ton}$ DS, $2.0 \mathrm{~kg} / \mathrm{ton}$ DS and $2.3 \mathrm{~kg} / \mathrm{ton}$ DS. Polymer doses considered in the experimental study were selected based on the polymer consumption trend in Beenyup Wastewater Treatment Plant of Water Corporation, Perth, WA. The polymer used in the study has total solid concentration of $0.48 \%$ and $\mathrm{pH}$ of 7.0. Shear stress and viscosity profiles were found to increase with increasing polymer dose from $1.0 \mathrm{~kg} / \mathrm{ton}$ DS to $2.3 \mathrm{~kg} / \mathrm{ton}$ DS due to the increase in average floc size and network of polymersludge colloids making the solid phase more compact and dense as shown in Fig. 10(a) and (b). The growth of flocs is in favour of solid-liquid separation; however, the significant increase in power consumption due to very high apparent viscosity and shear force requirement during thickening and hindered settling due to very large and loosely held floc particles at high polymer dose of $2.3 \mathrm{~kg} / \mathrm{ton}$ DS makes high polymer consumption unfavourable (an overdose 24 
condition). Polymer dose of $2.0 \mathrm{~kg} / \mathrm{ton}$ DS resulted in faster settling; however, the settling rate was much faster at lower polymer doses of $1.5 \mathrm{~kg} / \mathrm{ton}$ DS and $1.3 \mathrm{~kg} /$ ton DS with significantly reduced shear stress requirement and viscosity as shown in Fig. 10. The rate of settling decreased at poly dose of $1.0 \mathrm{~kg} / \mathrm{ton}$ DS due to insufficient flocculation and smaller floc sizes. Hence, polymer dose of $1.3 \mathrm{~kg} / \mathrm{ton}$ DS was found to be the optimum for enhanced thickening and lesser cost of operation of the thickening unit due to reduced shear force, viscosity and polymer consumption.

(a)

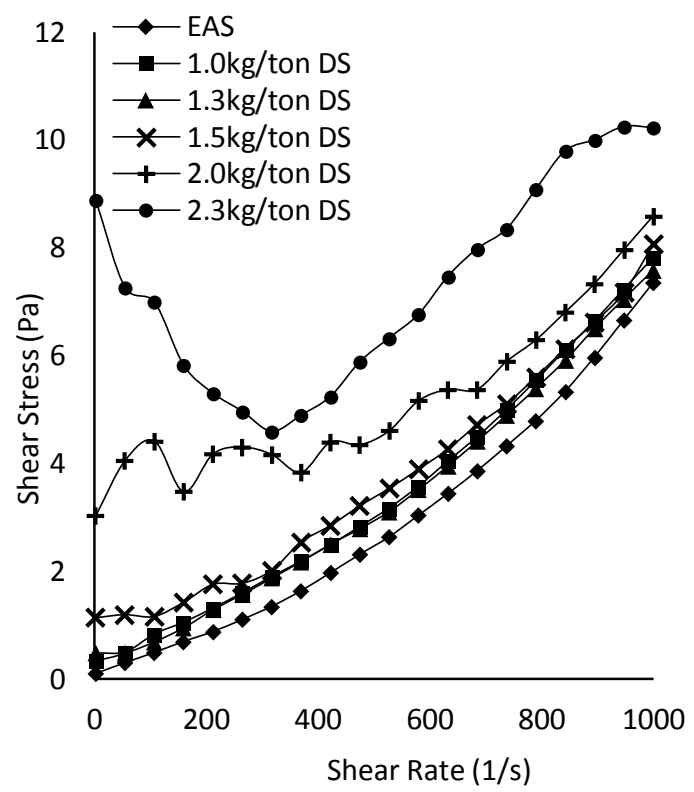

(b)

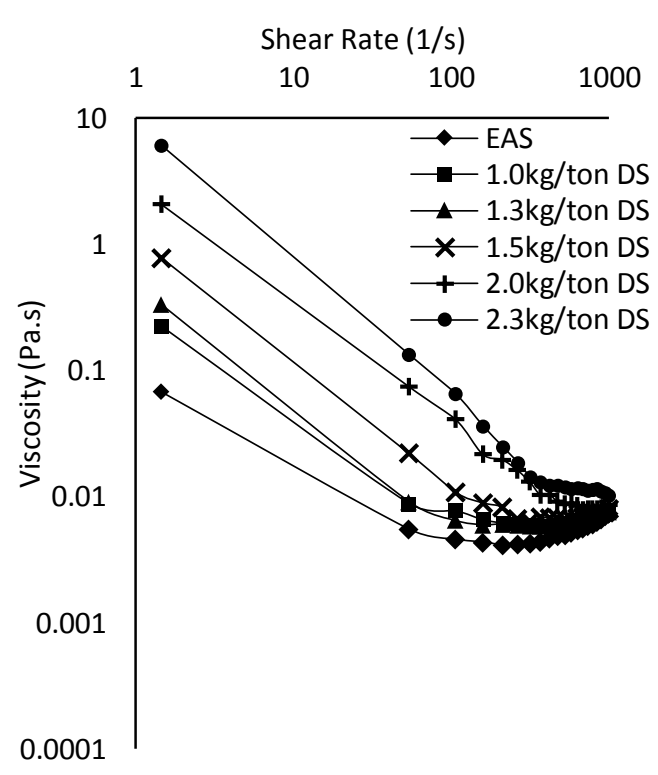

Fig. 10 (a) Shear stress-shear rate curves and (b) Viscosity-shear rate curves for different polymer dose of thickening of excess activated sludge at $\mathrm{T}=25^{\circ} \mathrm{C}, \mathrm{TS}=0.8 \% \mathrm{w} / \mathrm{w} \& \mathrm{pH}=7$ 


\section{Conclusion}

This study showed that concentration, temperature and $\mathrm{pH}$ are important parameters that significantly influence rheology of thickened excess activated sludge. The decrease in concentration from $3.7 \%$ to $3.1 \%$ resulted in drastic reduction of yield stress from $27.6 \mathrm{~Pa}$ to $11.0 \mathrm{~Pa}$. It further reduced to $1.3 \mathrm{~Pa}$ at total solid concentration of $1.3 \%$. The viscosity at the initial stage of shearing decreased from 26.4Pa.s for TS of 3.7\% to 4.8Pa.s for TS of $1.3 \%$ respectively according to Cross model. Yield stress steadily decreased from 20.1Pa to 8.3Pa when the temperature was raised from $23^{\circ} \mathrm{C}$ to $55^{\circ} \mathrm{C}$. Similarly, the initial viscosity of thickened excess activated sludge decreased from 15.24Pa.s to 3.49Pa.s with increase in temperature from $23^{\circ} \mathrm{C}$ to $55^{\circ} \mathrm{C}$. Higher activation energy requirement is associated with increased resistance to flow. The activation energy required at lower shear rate $\left(1.45 \mathrm{~s}^{-1}\right)$ was $25.1 \mathrm{KJ} \cdot \mathrm{mol}^{-1}$. The yield stress increased from $6.0 \mathrm{~Pa}$ to $8.3 \mathrm{~Pa}$ for a $\mathrm{pH}$ of 3.6 to $\mathrm{pH}$ of 10.0 respectively. The zero-rate viscosity was mostly constant around 3.9Pa.s to 4.9Pa.s for all the $\mathrm{pH}$ conditions considered in this study. Yield stress for thickened excess activated sludge was found to be very high 25.1Pa compared to mixed digester feed sludge, raw primary sludge and excess activated sludge according to Herschel-Bulkley model which all showed much lower yield stress of 2.6Pa, 1.9Pa and 0.2Pa respectively. The apparent viscosity also showed a similar decreasing trend with reduction of total solids and organic biomass content with the highest viscosity for thickened excess activated sludge at 26.6Pa.s and the lowest for excess activated sludge at 0.008Pa.s. Consequently, more rheological and flow analysis on thickened excess activated sludge rather than other sludge types helps to improve pumping cost, hydrodynamic mixing and mass transfer in digesters and ultimately the quality of the digested sludge and wastewater treatment plant economics. Besides, optimization of the polymer dose required for thickening of excess activated sludge is of great economic concern and the optimum polymer dose for excess activated sludge thickening was found to be $1.3 \mathrm{~kg} / \mathrm{ton}$ DS.

\section{Acknowledgements}

The authors acknowledge Water Corporation, Perth WA for providing onsite laboratory space and funding project (Project Agreement No. 008). Authors also acknowledge the Department of Chemical Engineering of Curtin University, Perth for proving necessary research infrastructure and Equipment/Instruments and financial support. 


\section{Reference}

1. N. Ratkovich, W. Horn, F.P. Helmus, S. Rosenberger, W. Naessens, I. Nopens and T.R. Bentzen Water Res. 47, 2 (2013)

2. F. Clauss, D. Helaine, C. Balavoine and A. Bidault Water Sci. Technol. 38, 8-9 (1998)

3. P. Trávníček and P. Junga Journal of Environmental Health Science and Engineering 12, (2014)

4. I. Seyssiecq, J.-H. Ferrasse and N. Roche Biochem. Eng. J. 16, 1 (2003)

5. F. Markis, J.-C. Baudez, R. Parthasarathy, P. Slatter and N. Eshtiaghi Chem. Eng. J. 253, 0 (2014)

6. B. Abu-Jdayil, F. Banat and M. Al-Sameraiy J. Water Resour. Prot. 2, 1 (2010)

7. S. Baroutian, N. Eshtiaghi and D.J. Gapes Bioresour. Technol. 140, 0 (2013)

8. E. Farno, R. Parthasarathy, J.C. Baudez and N. Eshtiaghi, in Chemeca 2013(2013)

9. F.D. Sanin Water SA 28, 2 (2002)

10. L. Piani, C.B. Rizzardini, A. Papo and D. Goi The Scientific World Journal 2014, (2014)

11. N. Eshtiaghi, F. Markis, S.D. Yap, J.-C. Baudez and P. Slatter Water Res. 47, 15 (2013)

12. H. Hasar, C. Kinaci, A. Ünlü, H. Toğrul and U. Ipek Biochem. Eng. J. 20, 1 (2004)

13. B. Liao, D. Allen, G. Leppard, I. Droppo and S. Liss J. Colloid Interface Sci. 249, 2 (2002)

14. E. Neyens, J. Baeyens, R. Dewil and B. De heyder J. Hazard. Mater. 106, 2-3 (2004)

15. B. Örmeci Water Res. 41, 6 (2007)

16. A. American Public Health, A. American Water Works, F. Water Pollution Control and F. Water Environment, Standard Methods for the Examination of Water and Wastewater, (American Public Health Association., 2005)

17. H. Li, Y. Jin, R. Mahar, Z. Wang and Y. Nie Bioresour. Technol. 99, 11 (2008)

18. V. Lotito and A.M. Lotito Journal of Environmental Management 137, 0 (2014)

19. A. Björn, A. Karlsson, B.H. Svensson, J. Ejlertsson and P.S. de La Monja, Rheological characterization, (InTech, Rijeka, Croatia, 2012)

20. L.I. Sokolov Life Science Journal 10, 4 (2013)

21. M. Mori, I. Seyssiecq and N. Roche Process Biochem. 41, 7 (2006)

22. A.H. Khalili Garakani, N. Mostoufi, F. Sadeghi, M. Hosseinzadeh, H. Fatourechi, M.H. Sarrafzadeh and M.R. Mehrnia Iran. J. Environ. Health Sci. Eng. 8, 3 (2011) 
23. M.A. Rao, Rheology of fluid and semisolid foods: principles and applications: principles and applications, (Springer Science \& Business Media, 2010)

24. L. Spinosa and V. Lotito Adv. Environ. Res. 7, 3 (2003)

25. L. Appels, J. Degrève, B. Van der Bruggen, J. Van Impe and R. Dewil Bioresour. Technol. 101, 15 (2010)

26. E. Paul, P. Camacho, D. Lefebvre and P. Ginestet Water Sci. Technol. 54, 5 (2006)

27. O. Manoliadis and P.L. Bishop J. Environ. Eng. 110, 1 (1984)

28. M.W. Tenney and W. Stumm Journal (Water Pollution Control Federation) 37, 10 (1965)

29. P.T. Spicer and S.E. Pratsinis Water Res. 30, 5 (1996) 